\title{
NóS E LINHAS: PESQUISANDO A RELAÇÃO FAMÍLIA-EQUIPE ${ }^{\star}$
}

\section{Roberta Carvalho Romagnoli ${ }^{\star}$ Nina Rosa Magnani ${ }^{\star \star \star}$}

\begin{abstract}
RESUMO
Esse texto apresenta os resultados parciais da pesquisa-intervenção financiada pela FAPEMIG, que tem como objetivo problematizar as relações no território equipefamília, evidenciando o que dificulta a participação da família no tratamento das crianças atendidas no Centro Psicopedagógico Renato de Avelar Azeredo-CPPde Nova Lima, como demanda da equipe de profissionais. Nesse contexto, examina o percurso trilhado com a equipe de profissionais, refletindo acerca de nossas intervenções como um intercessor para a criação de outra relação com esses grupos. Para tal, utiliza um caso clínico analisado em seus movimentos e vetores, perseguindo as linhas ora estratificadas, ora inventivas, que atravessam esse plano de forças. Embora a terapia familiar seja somente uma forma de se trabalhar com famílias, concluímos que o processo promoveu efeitos potencializadores na equipe, gerando outra forma de se conectar com esses grupos.
\end{abstract}

Palavras-chave: pesquisa-intervenção; esquizoanálise; família; processos de subjetivação.

\section{LINES AND KNOTS: RESEARCHING THE RELATIONSHIP FAMILY-TEAM}

\begin{abstract}
This paper presents the partial results of the intervention-research financed by FAPEMIG, that has the goal of problematize the relations in the territory teamfamily, highlighting the difficulties of the family's participation in the treatment of children assisted at the Centro Pedagogico Renato de Avelar Azevedo - CPP - in Nova Lima city, as a request of the professional team. In this context, it examines the route followed with the team of family therapy, reflecting about our interventions as an intercessor for the creation of another relationship with these groups. For that it uses a clinical case analyzed in its movements and vectors, pursuing lines sometimes entrenched, sometimes inventive, crossing the plane

^Apoio Financeiro: Fundação de Amparo à Pesquisa de Minas Gerais - FAPEMIG e Conselho Nacional de Pesquisa com bolsa de iniciação científica PICBIC.

$\star \star$ Psicóloga. Doutorado em Psicologia (Psicologia Clínica) pela Pontifícia Universidade Católica de São Paulo e pós-doutorado em Análise Institucional pela Université Cergy-Pontoise, França. Atualmente é Professor Adjunto III da Pontifícia Universidade Católica de Minas Gerais. Endereço: Pontifícia Universidade Católica de Minas Gerais, Departamento de Psicologia. Rua Dom José Gaspar. Coração Eucarístico. Belo Horizonte, MG - Brasil. CEP: 30535-610.

E-mail: robertaroma@uol.com.br

$\star \star \star$ Psicóloga. Mestre em Psicologia pela Pontifícia Universidade Católica de Minas Gerais, exDiretora e atual Coordenadora de projetos psicossociais do Centro Psicopedagógico Renato de Avelar Azeredo da Prefeitura Municipal de Nova Lima. Endereço: Prefeitura Municipal de Nova Lima. R. Poços de Caldas, s/n - Campo do Pires. Nova Lima, MG - Brasil. CEP: 34000-000. E-mail: ninamagnani@yahoo.com.br
\end{abstract}


of forces. Although family therapy is only a way of working with families, we conclude that this process generated enhancement effects on the team, creating another way to connect with these groups.

Keywords: intervention-research; schizoanalysis; family; subjectivation process.

\section{DO CAMPO E DA PROPOSTA}

Esse trabalho tem como objetivo apresentar os resultados parciais da pesquisa intervenção, financiada pela Fundação de Amparo à Pesquisa de Minas Gerais - FAPEMIG, que busca configurar e problematizar as relações no território equipe-família, evidenciando o que dificulta uma efetiva participação da família no tratamento das crianças atendidas no Centro Psicopedagógico Renato de Avelar Azeredo - CPP - da Prefeitura de Nova Lima. Essa instituição foi fundada há 25 anos e presta atendimento nos campos da saúde e educação. Localizada nessa interface, atende a crianças e adolescentes na saúde mental infantil, além de atuar em creches e escolas com abordagem psicossocial e institucional de situações que envolvam educadores, crianças e familiares. Sua equipe é composta por um psiquiatra, psicólogos, assistentes sociais, fonoaudiólogos, psicopedagogas e um terapeuta ocupacional. Em seu cotidiano de trabalho tem dificuldades em conseguir uma parceria efetiva, em algumas modalidades de trabalho, com as famílias de seus usuários.

A metodologia utilizada nesse estudo é a da pesquisa intervenção, a partir de uma abordagem cartográfica. Para tentar apreender mesmo que transitoriamente a complexidade na pesquisa, pode-se trabalhar com a cartografia, método utilizado em pesquisas de campo voltadas para o estudo da subjetividade e baseado na Esquizoanálise, também chamada Filosofia da Diferença (FONSECA; KIRST, 2003; KASTRUP, 2008; PASSOS; KASTRUP; ESCÓSSIA, 2009). Em contraposição a uma forma de pensar dicotômica, e fundamentando-se nas ideias de Gilles Deleuze e Félix Guattari, essa vertente convoca a imanência, a exterioridade das forças que atuam na realidade, buscando conexões, abrindo-se para o que afeta. Nesse sentido, a subjetividade deve ser pensada como um sistema complexo e heterogêneo, constituído não só pelo sujeito, mas também pelas relações que este estabelece, que atuam rizomaticamente, de uma maneira transversal, ligando-a processualmente a situações, ao coletivo, ao heterogêneo (GUATTARI, 1992).

Esse raciocínio aborda a realidade através de superfícies, de planos simultâneos de formas e forças. O plano das formas, também chamado de plano de organização, corresponde ao que está instituído socialmente, ordenando o mundo e a subjetividade em segmentos, estratos, homogeneizando as forças, os fluxos heterogêneos da vida. Por outro lado, o plano de consistência, das forças, é o plano invisível de expansão da vida, composto pelas forças moleculares que atravessam o campo social, dimensão dos encontros que vão gerar novos sentidos. De acordo com Deleuze e Guattari (1996), esses dois planos são imanentes e povoados por fluxos, com composição distinta: segmentar, estratificada, no plano de organização e fluida, conectiva, no plano de consistência. Como ressaltam Deleuze e Parnet 
(1998), a forma estratificada detém a circulação da vida e opera cortes e recortes que produzem o modo da subjetividade se colocar no mundo, visando a estabelecer métodos de hierarquização e de organização. Por outro lado, a forma fluida é mutante e criadora e corresponde à possibilidade de agenciar, de criar outros territórios.

É preciso pontuar que, nessa perspectiva, são exatamente esses modos de funcionamento distintos que compõem um território. Como construção espacial subjetiva, o território comporta segmentos, estratos, formas, mas também fluxos, forças e agenciamentos, sendo, sobretudo, processo que se caracteriza por um permanente "tornar-se" e "desfazer-se". Em consonância com sua dimensão processual, no território há direção e movimento, territorialização e desterritorialização, homogeneização e caotização. Dessa maneira, nos alerta o geógrafo Haesbaert (2006, p. 111) que "Trata-se, por certo, da valorização das simultaneidades, dos devires e de um tipo específico de conexão , o do "rizoma", ou seja, muito mais os contextos e interações do que as filiações e as sucessões".

Fundamentados nessa perspectiva teórica abordamos o território equipefamília, em seus contextos e interações, em seus movimentos estagnações apostando na possibilidade de invenção, de desconstrução das formas instituídas para fazer irromper outra relação, outro pensar/fazer na saúde, guiados o tempo todo pela questão: como propiciar agenciamentos inventivos com as famílias? Nessa trajetória usamos os seguintes dispositivos de coleta de dados/intervenção: assembleias gerais mensais com toda a equipe do CPP e da pesquisa; assembleias parciais com parte da equipe que atende às famílias; entrevistas semiestruturadas com profissionais, entrevistas semiestruturadas com familiares, observação dos projetos realizados pela equipe; supervisão clínica e grupo de estudos com parte da equipe que atende às famílias. Todos esses procedimentos foram permeados pela análise das demandas, das implicações, dos atravessamentos e da transversalidade em conjunto com o campo de pesquisa.

Cabe assinalar ainda que a análise parcial contida neste texto constituiu uma produção conjunta da coordenação da pesquisa e da direção do CPP. A proposta de escrever a "quatro mãos" incrementou a conexão entre a produção de conhecimento e o campo de trabalho, entre os "especialistas" e os "profissionais", tentando abarcar visões distintas de um mesmo processo. A construção do texto funcionou como um analisador que trouxe em cena o campo de forças institucionais em que estavam presentes a relação com a produção de conhecimento e seus saberes/poderes, o cotidiano do CPP e o fim da pesquisa com todas as expectativas iniciais que foram geradas.

Nesse contexto, este artigo pretende apresentar pontos significativos do percurso coletivo efetuado nessa pesquisa-intervenção, que se esforçou por rastrear nós e desatar linhas, e também, rastrear linhas e desatar nós, em uma tentativa de que pudessem ser estabelecidas intercessões entre a equipe de pesquisa, a equipe do CPP e os familiares ali atendidos. 


\section{DOS NÓS E DAS LINHAS}

Certamente a pesquisa-intervenção cartográfica é um desafio, principalmente ao se tentar colocar na escrita o percurso singular, complexo e processual no qual essa proposta sustenta. É necessário pontuar que o caminho escolhido para apresentar esse percurso, que, com certeza contém lacunas e endurecimentos no propósito de cartografar o que se passou em parte nesse estudo, se inicia questionando o procedimento metodológico da entrevista que se mostrou um importante analisador dos limites metodológicos do modo de fazer pesquisa em psicologia. Em seguida, esse analisador colocou no centro da pesquisa o problema da vinculação das famílias com o cuidado e sua conexão com os profissionais, desafiando ao mesmo tempo a equipe e as diretrizes de cuidado preconizadas pelas políticas públicas. Nesse sentido, a imposição por outros programas sociais, do tratamento oferecido pelo CPP é usual, além da não comunicação entre a rede de saúde do município. A partir desses analisadores que emergiram do plano de forças que se formou no território composto pela equipe de pesquisa, pela equipe de profissionais e pelas famílias, questionamentos ganharam consistência, desestabilizaram formas instituídas de pensar e atuar e fizeram surgir algo novo.

A entrevista é um procedimento hegemônico de coleta de dados na maioria das pesquisas qualitativas em psicologia. É um instrumento que, se usado de maneira inventiva, tem a possibilidade de tornar-se parte do plano de consistência, convocando forças e potências. Todavia, um dos pontos que chamou a atenção da equipe de pesquisa foram os efeitos das entrevistas semiestruturadas no estudo, o que nos conduziu a indagar acerca de seu uso nessa pesquisa-intervenção. A entrevista fez parte do plano de organização, das formas estabelecidas de conhecer, compondo um enquadre em que lugares demarcados a priori, produziram narrativas pouco espontâneas. Investigamos o que poderia ter mantido essa forma estratificada, que empobreceu os dados coletados, uma vez que as respostas acrescentaram pouco e não conduziram a reflexões por parte dos entrevistados, como pretendíamos inicialmente. Acreditávamos que as entrevistas poderiam ser também um intercessor, desestabilizando certezas, que favorecessem a criação de zonas de indagações, propiciando a emergência de algo novo na relação dos profissionais e dos familiares. Em nosso caso, analisamos que a falta de experiência dos bolsistas em realizar entrevistas impediu que eles dessem voz aos questionamentos aflorados na situação de perguntas e respostas, que não estavam previstos no roteiro, insistindo nos lugares cristalizados em que o entrevistador pergunta o previamente estabelecido e o entrevistado somente responde, aquilo que, de certa forma, este já espera. Entendemos que essa situação remete ao fato de que estavam em jogo várias instituições e saberes, que atravessaram o nosso cotidiano de pesquisa e das quais nós éramos vetores de enunciação, ora nos endurecendo, ora para nos conectando com o CPP. Sem dúvida, o objeto de estudo sempre produz efeitos no pesquisador, comportando dimensões heterogêneas, dizendo das forças que nos atravessam e atravessam as instituições. Como nos lembra Baremblitt (1992), esse processo é denominado implicação. 
Além dessas implicações primárias, que correspondem a nossas implicações com o território pesquisado, Monceau (2008) pontua ainda as implicações secundárias, que possuem elementos institucionais que escapam à interlocução local e abrangem campos mais amplos, nesse caso, a universidade. Os bolsistas fizeram as entrevistas pautados também nas suas relações com os modelos de formação universitária dominantes, permeadas pelo aprendizado em sala de aula, nos estágios feitos, nas disciplinas cursadas. Essas relações muitas das vezes são sustentadas pela ideia de neutralidade do pesquisador, herança positivista do paradigma moderno, ainda bem presente no campo de produção de conhecimento científico e que se distancia da proposta metodológica deste estudo. ${ }^{2}$ Entendemos que a ideia da não interferência do entrevistador nas informações dadas, foi um dos pontos de impedimento que algo coletivo emergisse, impossibilitando que outras forças circulassem. A coordenação, por sua vez, não atinou para a necessidade de discutir previamente a importância de que as entrevistas produzissem efeitos que pudessem convocar deslocamentos nas subjetividades envolvidas, preocupada com o tempo e o cronograma da pesquisa, imersa no momento em que se encontra a pós-graduação brasileira. Centrada na necessidade de cumprir os prazos com a agência de fomento, de realizar a intervenção em associação com a sua escrita, essa lógica atual da academia determinou, em certa medida, o descuido com o instrumento. Nas universidades, e, sobretudo na pós-graduação há uma tendência dos programas, de seguirem uma lógica produtivista e quantitativa, sem avaliar os efeitos dessa geração de conhecimento, em detrimento inclusive de uma discussão política, como pontua Castro (2010).

Por outro lado, a análise feita do ponto de vista do CPP, sugeriu que as entrevistas com os profissionais foram pouco focadas e não investigaram, de fato, $\mathrm{o}$ trabalho com família no CPP, as modalidades já experimentadas, suas análises e seus pontos de conflito, as situações associadas e as estatísticas produzidas. Além disso, foi questionado se quem foi entrevistado tinha realmente os dados necessários acerca desse tema. A equipe de pesquisa optou por uma amostra aleatória, em que entrevistamos quem se voluntariou e, como o número de voluntários foi superior ao planejado, a escolha se deu por sorteio. Entretanto, mais do que examinar onde estaria a falha, todas essas reflexões por parte das duas equipes, nos conduzem a repensar o próprio uso da entrevista em uma pesquisa intervenção, modalidade de pesquisa cuja relação cotidiana com o campo, via participação das atividades, é de uma riqueza extrema. Essa relação foi defendida pela direção do CPP, que além de atuar como elemento de ligação entre a academia, o serviço e a prefeitura, acompanhou nossas inserções no campo. A imanência do nosso objeto de estudo, ao longo dessa produção de conhecimento se deu em múltiplas composições de forças, em que a dimensão micropolítica foi favorecida. Consideramos que essa fluidez circulou, de forma transversal, em algumas circunstâncias das assembleias, nas conversas informais, nas idas junto com a equipe nas atividades, nas supervisões clínicas e nos grupos de estudos, embora tenha circulado pouco nas entrevistas. Essa circulação resultou em movimentos produtivos e instigantes para todo o grupo envolvido. 
No processo da pesquisa foi exatamente uma entrevista não realizada que gerou uma gama de questionamentos, dados importantes e a possibilidade de uma intervenção mais efetiva, desatando "nós" na relação do CPP com as famílias. No dia marcado para a entrevista houve um atraso de ambas as partes, entrevistadora e entrevistada, além do atraso da mãe para o atendimento do filho, chegando esta já nervosa e agitada, o que causou um transtorno entre a usuária e o serviço. Essa mãe é portadora de transtorno mental e é atendida pelo Centro de Atenção Psicossocial CAPS, onde deveria fazer tratamento medicamentoso, o que não estava ocorrendo.

Segundo relatos da equipe do CPP, o principal efeito da resistência e desinteresse dos familiares ao tratamento se expressa nos atrasos e ausências dos pacientes às sessões, fato que perturba o processo terapêutico e os profissionais, culminando muitas vezes no desligamento ou abandono dos atendimentos. $\mathrm{O}$ caso aqui abordado, emblemático, traz, no seu recorte, situações e episódios comuns ao CPP e possivelmente, a muitos serviços que abordam crianças e adolescentes.

O episódio em questão foi levado para a assembleia geral, e colocamos a possibilidade de maior discussão com a equipe que atende famílias. Decidiu-se por uma assembleia parcial que contou com a presença de dois assistentes sociais, uma estagiária da assistência social e duas psicólogas, juntamente com a coordenação da pesquisa e uma bolsista de iniciação científica. Na ocasião estávamos iniciando a análise das entrevistas com famílias. Nessa análise todas as famílias elogiaram o atendimento prestado. Diante dessas questões a discussão foi sendo direcionada para o motivo pelo qual as famílias, apesar de reconhecerem o mérito do serviço e estarem satisfeitas com o trabalho, não participam e nem demonstram interesse em participar diretamente do tratamento.

É necessário salientar um equívoco que se formou durante a pesquisa: confundiu-se o procedimento de terapia familiar, novo no cotidiano profissional e rodeado de questionamentos e de insegurança por parte dos profissionais, recentemente nele envolvidos, com o universo do trabalho com a família no CPP, sempre desenvolvido, às vezes até contra as ordens das chefias, que não viam essa abordagem com "bons olhos". De acordo com a direção, o trabalho com famílias, desenvolvido pelo CPP nos seus 25 anos de história, não foi suficientemente abordado pelos procedimentos de pesquisa. Durante esses anos, até os dias de hoje, todos os profissionais mantêm contato com as famílias através de sessões de orientação e de escuta, para as quais as famílias, em geral, demonstram interesse e disposição, às vezes em excesso, trazendo constantemente suas próprias queixas, buscando ocupar toda a sessão da criança e do adolescente. Nesses casos é feito o encaminhamento do(s) familiar(es) para outras abordagens, dentro ou fora do CPP. Nesse contexto, as abordagens são: grupo de pais, com número de participantes e duração variados; atendimento individual dos pais ou responsáveis, às vezes com a participação de outros membros da família; grupos temáticos de curta duração, tais como, "pais adotivos", "adolescência", entre outros; grandes encontros em que todos os pais são convidados para participar de oficinas ou de discussões pertinentes sobre temas definidos a partir de consultas aos pais e 
encontros para comunicação e tomada de decisões administrativas. É preciso evidenciar esses trabalhos para que não se tenha a falsa impressão de que a pesquisa inaugurou o trabalho com famílias no CPP.

Cabe enfatizar que, das várias abordagens oferecidas aos familiares, a que apresenta maiores dificuldades em sua adesão é a terapia familiar ou de casal, pois estas implicam no deslocamento ou distribuição do foco terapêutico, antes restrito à criança ou adolescente. A partir da experiência do CPP, a terapia familiar desperta fantasias persecutórias e amedronta esses grupos. Geralmente os pais têm uma visão da instituição como lugar que trata exclusivamente dos filhos, em que a família se envolve somente como informante e acompanhante. Esse olhar costuma ser também o das escolas com relação aos alunos encaminhados ao atendimento, atribuindo aos meninos, patologias apartadas dos processos que as gestam. Essas leituras sustentam-se na concepção de sujeito individual, à parte e isolado das forças e movimentos que o cercam e produzem, o que resulta, quase sempre em posturas terapêuticas estigmatizantes e ineficazes.

Retornando à assembleia parcial, a discussão a princípio se deslocou para o âmbito pessoal, como se o motivo da dificuldade de se trabalhar com as famílias se devesse ao mau acolhimento de alguns profissionais. Apesar disso, o caso em questão foi retomado, ajudando a demarcar melhor essa relação "equipe-família" no campo da equipe, do coletivo e do institucional. Assim, um primeiro "nó" levantado foi a "imposição", como marca no cotidiano das famílias na relação com as políticas públicas do município, que segundo a equipe, não "escutam" as famílias. Muitas vezes os responsáveis são encaminhados sob pressão por órgãos da ação social, pelo Conselho Tutelar, pelo Judiciário, pelas escolas e "aceitam" o tratamento como forma de serem bem vistos e recebidos pelas autoridades relativas ao campo da Infância e da Juventude e pelos Programas de Transferência de Renda. O processo de acolhimento, no CPP, busca corrigir tais distorções através da Retificação da Queixa, momento em que a criança e sua família podem se expressar, formular uma demanda própria e se implicar com os atendimentos e encaminhamentos a serem feitos.

Continuando a discussão acerca da entrevista não realizada, foi observado que a relação dessa mãe com o CAPS também não era satisfatória, não sendo feito acompanhamento regular, devido ao não estabelecimento de um vínculo efetivo, construído com o CPP, instituição em que há uma demanda de atendimento, uma vez que a mãe insiste em entrar na sala durante a sessão dos filhos, solicitando atenção. Esta situação é vista pela equipe como negativa, como algo que perturba o andamento do caso e provoca uma discussão coletiva acerca da configuração do atendimento, da demanda da mãe, da criança, da instituição e da equipe, até chegarmos à conclusão de que seria pertinente um atendimento familiar. A equipe de profissionais, embora já tenha feito cursos desse tipo de intervenção, enuncia sua falta de segurança e sua pouca formação para abordar terapeuticamente as famílias.

Para a análise institucional, corrente institucionalista de René Lourau, que tem como objetivo analisar o campo de forças do instituído e do instituinte dentro de uma instituição, a oferta de serviços, está associada diretamente à formação que 
os especialistas possuem (LOURAU, 2004). É a partir da oferta que uma demanda é criada na população atendida e na equipe de trabalho. Demanda esta que diz respeito aos serviços ofertados pela equipe de profissionais, baseada na formação adquirida e que sustenta as atuações cotidianas do serviço. Ou seja, refletir acerca da oferta de trabalho é examinar, na proposta de serviços/intervenções, a criação da demanda por parte do profissional, nos usuários (ROCHA, 2006). Dando visibilidade à relação oferta/demanda em nosso campo de análise, acreditamos que a demanda de terapia familiar não se enuncia e tampouco aparece nas entrevistas com familiares, pela própria dificuldade da equipe em sustentar essa atuação.

Essa falta de confiança da equipe, também aponta para a falta de formação adquirida no âmbito universitário, sobretudo na graduação, embora esta seja cada vez mais exigida na sustentação das políticas públicas. Os profissionais da equipe relatam não terem visto esse tipo de intervenção em seus cursos universitários. Os profissionais que fizeram essa constatação pertenciam às áreas da psicologia e do serviço social. Ao examinar a formação dos psicólogos para atuar na saúde pública, Romagnoli (2006, online) confirma essa colocação, assinalando que:

a clínica aprendida nos cursos universitários ainda é uma clínica individual, sendo desconhecida ou desprivilegiada a atuação com grupo, criando sérios problemas, principalmente na saúde pública, que como vimos, é um campo que exige novas metodologias.

A autora ressalta ainda que esse desconhecimento é também da própria realidade das famílias que são atendidas nos serviços públicos, embora as práticas grupalistas e de terapia familiar sejam oriundas de diferentes tradições. Os códigos, crenças e dinâmicas de funcionamento das famílias das diferentes camadas sociais são distintos e devem ser levados em consideração pelos profissionais sob o risco de desqualificação da diferença pela ignorância, pois a maior parte dos profissionais pertence às camadas médias cujo modelo dominante ainda é a família nuclear. Por outro lado, a maior parte das famílias atendidas nesses serviços é das camadas baixas, e nesse contexto são estigmatizadas como desestruturadas, exatamente por sua singularidade. Sarti (2007) destaca que as famílias de camadas baixas apresentam configuração em rede e não em núcleo, e após o casamento, os vínculos com a família de origem tendem a continuar, sobretudo pela instabilidade das relações. Assim, quando há ruptura de uma relação, ocorre com frequência a circulação de crianças, com ativação dessa rede e coletivização das responsabilidades pelos menores. A noção de família se define em torno de um eixo moral que é caracterizado por aqueles com quem se pode contar e em quem se pode confiar. Não há relações com os parentes de sangue se não for possível dar, receber e retribuir, pois o grupo é fonte de apoio e ajuda frente ao desamparo social. Nesse contexto, é óbvia a dificuldade de se sustentar a ideia de um modelo de família.

Apesar desse desconhecimento acerca das famílias, a importância da formação também pode ser questionada, pois esta pode reforçar a ideia de que o saber garantirá a atuação do profissional, e dará certezas em um campo em que a desestabilização é temida. A esse respeito, Gilles Monceau, faz o seguinte aler- 
ta, em entrevista na UFF, "O que é certamente perigoso é confundir teoria com universidade, pois os universitários não são certamente aqueles que estão no melhor lugar para elaborar uma teoria da prática de certa profissão." (PASSOS et al, 2008, p. 314). Essa colocação nos conduz a duas vertentes de reflexão. Uma primeira, que diz respeito à cisão entre teoria prática, imposta pelo paradigma moderno, e muitas das vezes perpetuada pela formação universitária brasileira e uma segunda, que nos leva ao imaginário dos profissionais acerca do saber especializado, que muitas das vezes os coloca passivos e alienados frente à sua prática, assujeitados a um saber que eles não constroem.

No que se refere ao primeiro ponto em livro que contempla um debate sobre a universidade brasileira, Naomar de Almeida Filho, após realizar um percurso histórico da universidade no mundo e no Brasil, assinala que a arquitetura acadêmica vigente em nosso país, possui sérios problemas a superar (SANTOS; ALMEIDA FILHO, 2005). Entre eles, o autor destaca a dissonância da formação universitária com a conjuntura contemporânea, o que torna o conhecimento adquirido nesse viés anacrônico para o enfrentamento da realidade e de sua complexidade. Por outro lado, na segunda questão observamos que, de fato, o conhecimento científico tem seus limites e, certamente, há algumas práticas e saberes que se produzem fora dos cursos de formação universitários que são efetivos e possuem valor apesar de serem desqualificados pelo modo instituído de se fazer ciência. Essa desqualificação muitas das vezes é introjetada e os saberes que emergem nos contextos de experimentação das equipes e dos usuários são inferiorizados por eles mesmos.

$\mathrm{Na}$ assembleia parcial foi colocada a proposta de atendimento familiar desse caso, com acompanhamento pela coordenação de pesquisa, uma vez que esta possui formação e experiência nesse campo. Além da proposta de supervisão foi feita ainda a de um grupo de estudos que desse algum subsídio para as intervenções a serem efetuadas. A problematização dos efeitos dessas intervenções permaneceu constante durante todo o processo. Se, por um lado, de fato potencializamos e contribuímos para outra leitura da família e uma maior aproximação do grupo, por outro lado, até que ponto contribuímos para uma passividade frente ao conhecimento? Não corríamos o risco de subjugar com nosso conhecimento, de ser um exercício do saber em cima de um dito "não saber"?

$\mathrm{Na}$ verdade, ao longo do processo nos indagamos até que ponto essas intervenções podem ter funcionado em alguns momentos como um intercessor. Se temos de um lado a universidade com suas exigências, de outro o CPP inserido no mercado de trabalho com suas demandas e prestação de serviços, e de outro ainda as famílias com seus problemas e o percurso que devem trilhar para receber seus benefícios, quais intercessões se deram nessas interfaces? Pois, como nos lembra o filósofo Gilles Deleuze (1992, p. 156), "O essencial são os intercessores. A criação são os intercessores. Sem eles não há obra”. Para que ocorra essa intercessão é preciso a transformação do saber em um saber "menor", para que se possa passar algo entre os especialistas e as famílias, os pesquisadores e os profissionais, o professor e os alunos. O saber "menor" designa o que se efetua no molecular e é, sobretudo, um discurso da minoria, para o qual é necessário dar passagem, para que este ganhe consistência e produza conexões. A respeito da minoria, pode-se afirmar que: 
a minoria se define como conjunto não numerável, qualquer que seja o número de seus elementos. O que caracteriza o inumerável não é nem o conjunto nem os elementos; é, antes a conexão, o "e", que se produz entre os elementos, entre os conjuntos, e que não pertence a qualquer dos dois, que lhe escapa e constitui a linha de fuga (DELEUZE; GUATTARI, 1997, p. 173).

Ou seja, são os agenciamentos "entre” subjetividades, conhecimentos, práticas, encontros que convergem em processos que arrastam para o novo, para a diluição do plano de organização, das formas que classificam e sobrecodificam os sujeitos e suas inserções sociais. O estabelecido se opõe ao discurso da minoria, sendo que o "menor" se faz com intercessores.

Qual forma cristalizada estaria se diluindo na situação de oferta de supervisão e de formação de um grupo de estudo? O campo da clínica possui regras rígidas acerca da formação, usualmente a supervisão é dada por um profissional experiente em seu consultório, que pertence a alguma entidade renomada e segue suas normas. Quando não é assim ocorre na universidade, nos cursos de graduação, para os discentes matriculados nos estágios sendo o professor responsável pela supervisão. Geralmente a supervisão é procurada pelos interessados e o profissional recebe honorários por essa atividade, seja como profissional autônomo seja como professor universitário. Nenhum desses formatos, dessas linhas duras foi seguido no CPP: o supervisor já estava no processo de pesquisa; a supervisão não era atrelada a nenhuma instituição e não havia honorários pela atividade. A vontade de ensinar e a coragem de se lançar em uma modalidade de atendimento desconhecida guiaram nossos encontros.

Por outro lado, o grupo de estudos era realizado quinzenalmente, com os mesmos participantes da supervisão, e seu objetivo era estudar a clínica de famílias. Seu conteúdo era articulado com a prática do atendimento e a supervisão. No nosso entender, esse grupo também formou um circuito paralelo à formação universitária e às associações de formação em que foi possível aprender e tivemos alguns intercessores potentes: os textos estudados, a experiência dos atendimentos anteriores, a disponibilidade para a imanência, a alegria. Este grupo desenvolveu vários ritmos. Lento e extensivo no horário, no deslocamento, no excesso de atividades em que estava inserido. Mas acelerado e intensivo no conhecer e ser afetado pelo que não se sabe ressonando no que se sabe. Todos aprenderam: os bolsistas de iniciação científica viam a articulação do que é estudado na universidade com a prática, sobretudo com os exemplos do cotidiano que surgiam, os profissionais, por sua vez, retomavam o hábito do estudo, com a possibilidade de pensar suas atuações, e a coordenadora/professora com a vida se movimentando fora do circuito repetitivo da academia.

Esse circuito paralelo na maioria das vezes burlou as formas estabelecidas/ previstas de se aprender clínica, e nos fez questionar até que ponto essas formas não exigem a priori uma obediência, que pode sufocar as potencialidades inventivas da clínica. Será que em um momento em que a realidade cada vez 
mais nos convoca a criar outras intervenções e a lidar com a complexidade, esse pendor à submissão não caminha na direção contrária: a da reprodução? A seguir, apresentamos o caso clínico, em torno do qual a supervisão e o grupo de estudos gravitaram, analisado em termos de movimentos e vetores, perseguindo as linhas ora estratificadas, ora inventivas, que atravessam esse plano de forças.

\section{Do Caso Ana}

A família de Ana, 40 anos e portadora de transtorno mental, é composta por Rui, de 23 anos, Débora, de 21 anos, Walter, de 12 anos, Wilson, de 11 anos e Lilian, de 8 anos. Os três últimos filhos fazem acompanhamento individual no CPP com psicólogas diferentes. A história de Ana é marcada por fortes conflitos com sua mãe, a avó dos meninos, que sempre desqualificou sua maternidade, tendo conseguido há cerca de 15 anos, no Comissariado de Menores, a guarda dos dois netos mais velhos. Na época, a avó construiu um quartinho nos fundos de sua casa para Ana, e os netos moravam na casa da frente com ela. Os outros três filhos vieram depois dessa perda, em uma tentativa de resgatar o lugar da maternidade. Contudo, em 2002, estes também lhe foram tirados, sob a alegação de negligência por problemas psiquiátricos, e conduzidos ao centro educacional, antiga Fundação Estadual do Bem Estar do Menor - FEBEM. Na ocasião, Ana foi considerada incapaz de cuidar de seus filhos.

Vale lembrar que o Comissariado de Menores atuava em uma época em que ainda não havia o Estatuto da Criança e do Adolescente - ECA (BRASIL, 2001) e tampouco a Lei Orgânica de Assistência Social - LOAS - (BRASIL, 2003). Conforme Frota (2002), as primeiras legislações e instituições específicas destinadas à infância e à adolescência surgiram nos países europeus e americanos, no final do século XIX, início do século XX, baseadas na mesma doutrina que regia o Comissariado de Menores em nosso país - a "doutrina da situação irregular". Essa doutrina objetivava o controle social, tanto dos "menores" infratores quanto dos abandonados moral ou materialmente. Nesses casos, o juiz tinha o poder de intervir diretamente no cotidiano das famílias, estabelecendo o destino de suas crianças. Essa doutrina se instala no Brasil com o Código de Menores Mello Mattos,de 1927, e permanece com o Código de Menores de 1979, só sendo substituída, pelo menos formalmente, pela "doutrina de proteção integral” com o ECA de 1990.

Tanto o ECA quanto a LOAS propiciaram uma guinada na proposta vigente, consolidando a assistência social como uma política pública que visa a garantir a todos, que dela necessitarem, sem contribuição prévia, a proteção social, sustentando-se nas pessoas, nas suas circunstâncias e na família, para assegurar os direitos e promover a cidadania em segmentos excluídos da sociedade. Na decisão que atravessou a família de Ana, não havia essa proposta, tampouco a ação das entidades responsáveis pela execução de programas de proteção eram fiscalizadas pelos conselhos municipais de direitos e pelo Conselho Tutelar. Essa sentença foi vivenciada por Ana como punição. Ana não foi escutada, ideias moralistas circularam, estra- 
tos se consolidaram. Os filhos ficaram institucionalizados em torno de cinco anos. "Será que a família como se encontra hoje foi fruto dessa incoerência?", indaga uma das terapeutas, na primeira supervisão após o primeiro atendimento do grupo.

Presenciamos aqui a ação por atravessamento em que:

a rede social do Instituído-Organizado-Estabelecido, cuja função prevalente é a reprodução, atua em conjunto. Cada uma das entidades opera na outra, pela outra, para a outra, desde a outra. Este entrelaçamento, interpenetração de orientação conservadora, serve à exploração, dominação e mistificação, apresentando-as como necessárias e benéficas (BAREMBLITT, 1992, p. 156).

No caso de Ana, o aparato jurídico, a assistência social, a sua família, se entrelaçaram para tirar-lhe seus filhos. Ana reclamou, brigou, mas não adiantou. Ela ia ver Walter, Wilson e Lilian, com frequência. Reclamava quando os monitores do centro educacional não cuidavam de seus filhos, deixando-os com nariz sujo, mal arrumados. Não respeitava o horário de visitas, pois alegava que era mãe e queria vê-los. Achava que tinha esse direito e o exigia. A diretora, sensível, deixava, ouvia suas reclamações e chamava a atenção dos cuidadores. Ana tinha brigas constantes com a sua mãe, pois queria os filhos mais velhos de volta. A mãe a desqualificava, a boicotava. Depois de muita luta, Ana consegue ganhar uma casa em um programa habitacional da prefeitura e levar os filhos menores. Quer ser mãe, afirmar esse lugar. Insiste. Depois de um ano morando na casa nova, Rui e Débora decidem largar a avó, que os criava, e também irem.

“C., me ensina a ser mãe?". A frase ecoa em um encontro com uma das terapeutas antes de decidirmos atender a família. Tem um só jeito de ser mãe? Ana expressa o que Foucault (2004) denomina de naturalização, enunciado de verdades calcadas em conhecimentos científicos. Ao propor o uso da genealogia como método de pesquisa, o referido autor busca a desnaturalização, a destruição das origens, das verdades imutáveis embasadas no saber. Defende um olhar político que evidencia as relações de poder que fazem com que certas coisas tidas como verdadeiras, sejam ditas como algo tomado/produzido como objeto de saber. A partir da análise dessas relações é possível desmontar/contextualizar as verdades imutáveis e estudar as formas de poder na sua complexidade. O que atravessa a fala de Ana? A certeza de que a especialista sabe como criar filhos, embasada em seus estudos? O saber esmagando a possibilidade de emergir a singularidade de exercer essa função? Ana busca uma verdade, que acabe com seu desassossego.

A dimensão histórica em torno da maternidade, no nosso entender, esclarece, provisoriamente, como nos constituímos como sujeitos em busca da verdade, muitas vezes amparada nos discursos científicos e em suas práticas, como parece ser o que Ana almeja. A modernidade traz em seu bojo a ideia de uma mãe dedicada, que ame incondicionalmente seu filho, como ressalta Badinter (1985). O sentimento de infância, assim como a reestruturação da concepção de maternidade, emerge, sobretudo no século XVII, uma vez que era necessário, para a 
ascensão da burguesia, a sobrevivência dos filhos e a consequente transmissão da propriedade privada. Nesse contexto, o cuidado com as crianças deveria ser executado pela mulher. Ser "boa" mãe torna-se fundamental e a mulher é chamada a exercer a maternidade voltando-se para as necessidades de seu filho. Esse papel é incrementado por discursos e produções científicas.

No Brasil, assistimos ao surgimento e à consolidação desse novo papel a partir da emergência da vertente higienista no século XIX, estudado por Costa (1989). Com a ascensão do saber científico, principalmente na medicina, houve uma ênfase na necessidade de melhores condições de vida e de higiene, para a manutenção da saúde física e mental da população. Nesse contexto, os higienistas vão valorizar a privacidade, a saúde doméstica e a interiorização dos indivíduos, destacando a importância do papel da mulher como mãe responsável e a necessidade da família de se preocupar com os filhos, que carecem ser criados com cuidado, afeto e saúde. Atualmente, ao estudar a relação entre família e instituições de saúde, no que se refere aos sentidos da maternidade, Moura e Araújo (2005) afirmam que ainda se percebe a existência desse modelo ideal de maternidade e a grande ênfase na ação da mulher, gestadas no movimento higienista. Esse modelo favorece a naturalização da maternidade, insistindo na abnegação, na disponibilidade e na afetividade para a manutenção do vínculo entre mãe e filho, como se essas características fossem universais e a-históricas. Essa forma dominante, muitas das vezes sustentada também pelos profissionais "psi", compõe a dimensão do plano de organização como se houvesse apenas uma forma de ser mãe, mantendo a sensação de culpa e de incapacidade, que por vezes parece envolver Ana e impedir que sua forma singular de ser mãe ganhe consistência.

Na primeira sessão de família todos vão, falam, participam. As terapeutas ficam espantadas - "São uma família com metas!". Respeitam-se, querem ficar juntos. A mãe é amorosa e o fato de possuir transtornos mentais não parece diminuí-la perante os meninos. Ana se preocupa com o fato de Rui e Débora sustentarem a casa. Quer arrumar um emprego, mas não consegue. Ana não suporta os vizinhos. No bairro sofre "preconceito". Diz que é perseguida e que os filhos também, muitas das vezes chamados de "gardenal". Mesmo não dando confiança, os vizinhos a provocam. Só fazem isso quando ela está só.

Nessa sessão algo circula. Estabelece-se uma composição que não os julga, não os desqualifica como família, ao contrário, os acolhe. ${ }^{3}$ Por ser uma família atravessada por estigmas sociais, tais como, a doença mental, a negligência, a pobreza, usualmente são reconhecidos como uma família "desestruturada" pelas instituições. Todos acham que podem emitir um parecer sobre como deveriam ser. De repente, a transcendência dilui-se na sessão, no encontro. Na justaposição de planos, das formas e das forças, a linha do cuidado emerge. Ora capturada pela impotência, pela sensação de que não pode cuidar. Ora convocando a união familiar, o cotidiano pautado nessa marca. Ana que não consegue cuidar, destituída do seu lugar de mãe, de sua possibilidade de inventar outra conexão com esse estado. Ana que cuida. Todos que se cuidam. Membros que não conseguem cuidar de si mesmo, sugados por essa demanda familiar de cuidado coletivo. 
Ana vai ao CAPS, mas não toma o medicamento, desvencilhando-se do assunto. Observamos aqui a dificuldade de comunicação entre a rede de saúde, presente em grande parte dos serviços. Os profissionais apontam para a falta de condições de sustentação dessa rede, pelo pouco diálogo e troca entre os profissionais. Essa ausência muitas vezes se dá pela ameaça vivida pelos setores e serviços em perder seu espaço e sua identidade, garantida pela atuação específica que lhes cabe. Para tentar sanar estes obstáculos, em 2008, o CPP fez a proposta, junto a vários órgãos e instituições, de criar o Fórum Municipal de Atenção à Criança e Adolescente, sendo realizada uma primeira reunião em que compareceram quatorze (14) entidades de diversos setores da rede pública de Nova Lima, tais como: Centro de Atenção Psicossocial (CAPS), Programa Saúde da Família (PSF), Centro de Referência em Assistência Social (CRAS), Centro de Referência Especializado de Assistência Social (CREAS), Conselho Tutelar, Programas de Transferência de Renda condicionada a Bolsa Família e Vida Nova, dentre outras. Depois de algumas reuniões, esse fórum se esvaziou e não foi levado a cabo. Atualmente o mesmo foi retomado, priorizando a discussão coletiva de casos e se isentando da discussão das políticas públicas do setor.

Entre o primeiro e o segundo atendimento, ocorreu um episódio que nos fez pensar tanto na manutenção do que já existia na relação de Ana com o CPP quanto em certa esquiva da emergência do novo. No mesmo dia em que iria acontecer o segundo encontro com a família, os filhos avisaram que não poderiam ir e Ana foi ao CPP, desorientada, por causa de uma briga com os vizinhos. Busca o atendimento individual, com uma das terapeutas de família que a acompanhou em muitas instituições pelas quais ela já passou e quer solucionar os problemas do seu dia-a-dia. Essa conduta mantém tanto o esvaziamento do tratamento familiar quanto o afastamento da procura do serviço de saúde mental. É importante que as dificuldades de Ana apareçam no grupo familiar, pois é preciso ver como isso afeta a todos os membros e quais saídas são ou não construídas. Colocar a família ativa nesse processo é um desafio, bem como sustentar novas formas de intervenção.

Embora nestes dois encontros, a família foi se sentindo acolhida, tendo espaço para se falar, expor sua forma de funcionamento, partilhar seus problemas, efetivamente, os profissionais tiveram dificuldades com a ida da família, depois do último encontro. Tentaram marcar duas vezes sem sucesso, pois os irmãos mais velhos não conseguem tempo para ir, e a mãe com os outros meninos não comparecia. Os técnicos envolvidos ficaram decepcionados. Uma das psicólogas levantou dois atravessamentos que perpassam essa desistência: o perfil do CPP e da psicologia em geral de trabalhar somente centrado no atendimento das crianças e adolescentes e o grande período de férias do serviço, acompanhando as férias escolares, pelo atrelamento à secretaria de educação. Além dessas dimensões, que, com certeza, estavam presentes, no viés clínico analisamos que o atendimento foi entendido também como uma ameaça à dinâmica familiar. O início do boicote ao tratamento se deu através dos filhos mais velhos, que parecem não o verem como importante. Levantamos aí a hipótese de uma aliança com a família de origem de Ana, na figura da avó que sempre desqualificou-a como mãe, e também às suas duas outras filhas, 
que também têm filhos atendidos no CPP. Todas elas com graves problemas emocionais e com grande dificuldade em ser mães. Todas possuem uma devoção aos filhos, mas uma forte sensação de incapacidade na sustentação desse lugar.

Como possibilidade de atuação a partir dessa discussão, decidimos chamar a avó para uma entrevista, em uma tentativa de continuar com a intervenção familiar. No entanto, essa decisão teve um desencadeamento completamente inesperado, pois a avó se escondeu dos telefonemas efetuados inúmeras vezes pelas terapeutas em horários distintos. Não quis saber do que se tratava, mas começou a culpabilizar Ana pela chamada no CPP, acusando-a de que não estar tomando conta direito de seus filhos e ameaçando retirá-los novamente da convivência com ela. Ana tentou falar com uma das terapeutas, mas houve desencontros. Em uma de suas procuras, recebeu a notícia de que essa terapeuta havia ido ao fórum, e imaginou que era para denunciá-la e que ela iria, de fato, perder seus filhos, como a mãe havia dito. A fantasia ganhou proporções imensas na família, e os filhos passaram inclusive a defender a mãe, em seus atendimentos individuais, pois sentiram a família ameaçada. E as terapeutas sem nada saber. Até que um dia, houve o tão esperado encontro e a confusão foi desfeita. Esse desfecho tornou evidente para nós a falta de fronteiras nítidas entre a família de Ana e a sua família de origem, sendo que a avó possui um grande poder de interferência no cotidiano do grupo, mantendo, sempre que possível, o lugar de Ana na família como incapaz e nociva para os filhos.

Esse episódio reforçou a idéia, que havíamos tido no encontro anterior, de trabalhar com um grupo de avós. No CPP há vários membros da terceira geração de uma mesma família sendo atendidos, e, nesses casos, pensamos que trabalhar as avós pode ser um ponto produtivo. A idéia foi levada para a assembléia geral e aprovada, e já se encontra na fase de receber encaminhamentos.

Nessa supervisão discutimos ainda o porquê da família não querer continuar o tratamento. Uma das terapeutas fez a leitura de que foi uma decisão de autonomia da família, como se estivessem falando: "Nós vamos dar conta de nossa família". E, nesse sentido, era importante evitar uma atitude assistencialista, e deixar a família fazer seu movimento. Essa colocação foi feita dada à preocupação crescente com a interferência constante das políticas sociais no cotidiano familiar, sustentando ações de intromissão e de certa forma, desqualificação das famílias. Esse é um ponto crucial que Sawaia (2007) levanta como dificuldade de se trabalhar o protagonismo social das famílias pobres. Nas palavras da autora: “As ações comunitárias e políticas públicas planejam ações como se os pobres não tivessem necessidades elevadas e sutilezas psicológicas." (SAWAIA, 2007, p. 45). Manter esse olhar é abarcar a família de risco ou a família incapaz e não a família que sofre.

O caso Ana terminou com um fechamento com a mãe, após inúmeras tentativas, falando do processo e do percurso terapêutico, e ressignificando positivamente a ausência da família como possibilidade de cuidar deles próprios. Após esse fechamento foi feita uma auto-análise com a equipe de famílias. Acerca do processo da pesquisa avaliamos que as intervenções feitas nas assembléias, na supervisão e no grupo de estudo provocaram efeitos, não só nas famílias, mas na própria equipe 
de profissionais e também na equipe de pesquisa. Esse percurso, segundo os profissionais ampliou muito a análise do grupo familiar e dos casos. Inclusive já estão ocorrendo posturas e intervenções diferentes com outros casos atendidos no CPP.

\section{Considerações Finais}

Ao longo de nossa pesquisa procuramos conhecer as relações no território equipe-família, no intuito de lá criar outras conexões e outras práticas de cuidado, além de identificar o que se repete de maneira a impedir essa criação. Em nossos encontros ficou claro que a equipe de profissionais questionava seu saber fazer, insistia em sua falta de conhecimento para o trabalho com o grupo familiar e destacava a dificuldade de sustentar um trabalho em rede no município. Esses pontos atravessavam a relação com a família nesse território. De fato, a realidade do trabalho cotidiano no âmbito das políticas públicas traz consigo a necessidade de conexão com esse grupo. Arriscar atuar com a família, também se ajusta às altas demandas de atendimentos presentes não só no $\mathrm{CPP}$, mas em todas as instituições públicas, incidindo diretamente sobre a problemática da criança e do adolescente. No entanto, essas atuações são pouco difundidas na formação universitária, que ainda transmite uma clínica dominantemente individual, se distanciando das demandas das políticas públicas.

Em nossa pesquisa, cujo foi divulgado nesse texto, esperamos ter conseguido nem que seja em algumas conexões, operar como intercessores no cotidiano dessa equipe, favorecendo que outros acoplamentos com a família se fizessem. Todo esse processo nos permitiu constatar a importância da pesquisa-intervenção na tentativa de construir outros parâmetros que nos permitam conhecer, mesmo que parcialmente o que se passa nos espaços de atuação dos trabalhadores sociais, perseguindo a transformação processual do campo de pesquisa, desarticulando práticas e discursos instituídos para que surja algo novo. Tentamos associar produção de conhecimento e realidade/campo de pesquisa, atentos aos efeitos ético-políticos dessa associação, rastreando, mesmo que de maneira inacabada e provisória os nós e linhas que atravessaram o território equipe de pesquisa-profissionais-família.

Apesar de muitas das vezes a estratégia cartográfica ter ficado perdida em meio à complexidade do território estudado e aos endurecimentos de nossas inserções institucionais, não evidenciando o molecular, acreditamos na singularidade e na invenção. Essas dimensões atuam, no nosso entender, como apostas para arriscar novas maneiras de se fazer ciência com o intuito de abordar o plano de forças que se instala na própria relação entre pesquisador e pesquisado. Sem dúvida, teoria e prática produzem e são produzidas nos encontros, compondose de dimensões ora estratificadas ora fluidas que denunciam a heterogeneidade do nosso campo de pesquisa, vislumbrada parcialmente no caso Ana. Desvelam ainda formas e forças presentes nesses encontros e que nos fazem pensar, de que conexões as equipes, as famílias e os serviços são capazes. 


\section{Notas}

${ }^{1} \mathrm{O}$ termo analisador foi criado inicialmente por Félix Guattari na Psicoterapia Institucional, mas foi incorporado e bastante usado na Análise Institucional. Os analisadores correspondem a elementos da realidade social que expressam as forças das instituições e do sistema social e podem ser entendidos como efeitos ou fenômenos que emergem dessa processualidade, sendo usualmente porta-vozes dos conflitos de um território. Ao irromper, desvelam a reprodução do instituído, mas também produzem o impensado, o novo.

${ }^{2} \mathrm{O}$ paradigma moderno sustenta a fundação da ciência e sua manutenção e insiste no conhecer pela razão através da sistematização, do rigor e da objetividade. Nesse sentido, a ciência busca a explicitação de verdades acerca do seu objeto de estudo, embora cada ciência opere, de fato, recortes acerca dessa realidade, reducionismos sustentados por determinada corrente teórica e/ou metodológica. Opera ainda uma cisão entre teoria e prática, pois o conhecimento se coloca separado da atuação (VEIGA-NETO, 2002).

Entendemos aqui acolhimento não como atitude voluntarista, de bondade e favor por parte de alguns profissionais geralmente exercido na triagem para repasse de encaminhamentos, mas como prática que se efetua na intercessão, no encontro entre formas e forças e sustenta as práticas de cuidado (NEVES; HECKERT, 2010).

\section{REFERÊNCIAS}

BADINTER, E. Um amor conquistado: o mito do amor materno. 5. ed. Rio de Janeiro: Nova Fronteira, 1985.

BAREMBLITT, G. Compêndio de Análise Institucional e outras correntes. Rio de Janeiro: Rosa dos Tempos, 1992.

BRASIL. Casa Civil. Código de Menores Mello Mattos. Decreto no $17.943-\mathrm{A}$ de 12 de outubro de 1927. Disponível em: <http://www.planalto.gov.br/ccivil_03/ decreto/1910-1929/D17943A.htm>. Acesso em: 03 abr. 2010.

BRASIL. Casa Civil. Código de Menores. Lei no 6.697, de 10 de outubro de 1979. Disponível em: <http://www.planalto.gov.br/ccivil_03/leis/1970-1979/ L6697.htm>. Acesso em: 05 abr. 2010.

BRASIL. Estatuto da criança e do adolescente. 10 ed. Rio de Janeiro: Atlas, 2001. (Legislação Brasileira).

BRASIL. Lei orgânica da assistência social - 1993 - LOAS. 2 ed. Brasília: Ministério Público da Previdência e Assistência Social/Secretaria de Estado da Assistência Social, 2003.

CASTRO, L. R. Políticas científicas e modos de subjetivação do pesquisador: um outro mundo (acadêmico) é possível? In: ENCONTRO NACIONAL DA ANPEPP, 13., 2010, Fortaleza. Anais... Fortaleza: [s. n.], 2010.

COSTA, J. F. Ordem médica e norma familiar. 3. ed. Rio de Janeiro: Graal, 1989.

DELEUZE, G. Conversações. Rio de Janeiro: Ed 34, 1992. 
DELEUZE, G.; GUATTARI, F. 1933: micropolítica e segmentaridade. In: 3, p. 83-115. . Mil Platôs: capitalismo e esquizofrenia. Rio de Janeiro: Ed. 34, 1996. v.

DELEUZE, G.; GUATTARI, F. 7000 AC - Aparelho de captura. In: . Mil Platôs: capitalismo e esquizofrenia. Rio de Janeiro: Editora 34, 1997. v. 5, p. 111-177.

DELEUZE, G.; PARNET, C. Diálogos. São Paulo: Escuta, 1998.

FONSECA, T. M. G.; KIRST, P. G. (Org.). Cartografias e devires: a construção do presente. Porto Alegre: UFRGS, 2003.

FOUCAULT, M. Nietzsche, a genealogia e a história. In: . Microfísica do poder. 20. ed. Rio de Janeiro: Graal, 2004. p. 15-37.

FROTA, G. da C. A cidadania da infância e da adolescência. In: CARVALHO, A. et al. (Org.). Políticas públicas. Belo Horizonte: UFMG/PROEX, 2002. cap. 3 , p. 59-85.

GUATTARI, F. Caosmose: um novo paradigma estético. Rio de Janeiro: Ed. 34, 1992.

HAESBAERT, R. Território e desterritorialização em Deleuze e Guattari. In: . O mito da desterritorialização. Rio de Janeiro: Bertrand Brasil, 2006. $\overline{\text { p. } 99-141 .}$

KASTRUP, V. O método da cartografia e os quatro níveis da pesquisa-intervenção In: CASTRO, L. R.; BESSET, V. L. (Org.). Pesquisa-intervenção na infância e juventude. Rio de Janeiro: Trarepa/FAPERJ, 2008. p. 465-489.

LOURAU, R. Objeto e método da Análise Institucional. In: ALTOÉ, S. (Org.). René Lourau: analista institucional em tempo integral. São Paulo: Hucitec, 2004. p. 66-86.

MONCEAU, G. Implicação, sobreimplicação e implicação profissional. Fractal: Revista de Psicologia, Niterói, v. 20, n. 1. p. 19-26, jan./jun. 2008.

MOURA, S. M. S. R. de; ARAÚJO, M. de F. Produção de sentidos sobre a maternidade: uma experiência no Programa Mãe Canguru. Psicologia em Estudo, Maringá, v. 10, n. 1, jan./abr. 2005. Disponível em: <http://www.scielo.br/scielo. php? script=sci_arttext\&pid=S1413-73722005000100006\&lng=pt\&nrm=iso $>$. Acesso em: 02 mar. 2007. 
NEVES, C. A. B.; HECKERT, A. L. C. Micropolítica do processo de acolhimento em saúde. Estudos e Pesquisas em Psicologia, Rio de Janeiro, v. 10, n. 1, p. 151-168, 2010. Disponível em: <http://www.revispsi.uerj.br/v10n1/artigos/pdf/ v10n1a11.pdf>. Acesso em: 09 abr. 2010.

PASSOS E. et al. Entrevista com Gilles Monceau. Fractal: Revista de Psicologia, Niterói, v. 20, n. 1, p. 311-317, jan./jun. 2008.

PASSOS, E.; KASTRUP, V.; ESCÓSSIA, L. Pistas do método da cartografia: pesquisa-intervenção e produção da subjetividade. Porto Alegre: Sulina, 2009.

ROCHA, M. L. Psicologia e as práticas institucionais: a pesquisa intervenção em movimento. PSICO, Porto Alegre, v. 37, n. 2, p. 169-174, mai./ago. 2006.

ROMAGNOLI, R. C. A formação dos psicólogos e a saúde pública. Pesquisas e Práticas Psicossociais, São João Del Rey, v. 1, n. 2, dez. 2006. Disponível em: $<$ http://www.ufsj.edu.br/portal2-repositorio/File/revistalapip/RobertaRomagnoli. pdf $>$. Acesso em: 12 maio 2007.

SANTOS, B. de S.; ALMEIDA FILHO, N. de. A universidade do século XXI: para uma universidade nova. São Paulo: Cortez, 2005.

SARTI, C. A. Famílias enredadas. In: ACOSTA, A. R.; VITALE, M. A. (Org.). Família: redes, laços e políticas públicas. 3. ed. São Paulo: Cortez/IEC PUC SP, 2007. p. 21-36.

SAWAIA, B. B. Família e afetividade. In: ACOSTA, A. R.; VITALE, M. A. (Org.). Família: redes, laços e políticas públicas. 3. ed. São Paulo: Cortez/IEC PUC SP, 2007. p. 39-50.

VEIGA-NETO, A. Olhares. In: COSTA, M. V. (Org.). Caminhos investigativos: novos olhares em pesquisa em educação. Rio de Janeiro: DP\&A, 2002. p. 23-38.

Recebido em: 08 de julho de 2010

Aceito em: 18 de abril de 2012 